\title{
COUPLING MECHANISM OF VOLUME STRAIN AND WATER LEVEL IN THE FUXIN WELL LOCATED IN A GEOTHERMAL AREA BEFORE AND AFTER THE $2011 M_{W} 9.1$ TOHOKU EARTHQUAKE
}

\author{
Yan ZHANG ${ }^{1)}$ *, Li-Yun FU ${ }^{1)}{ }^{*}$, Lian-feng $\mathrm{ZHAO}^{1)}$ and Xuezhong CHEN ${ }^{2)}$ \\ 1) Key Laboratory of Earth and Planetary Physics, Institute of Geology and Geophysics, Chinese Academy of Sciences, No. 19, \\ Beitucheng Western Road, Beijing 100029, China \\ 2) Institute of Geophysics, China Earthquake Administration, No. 5 Minzu Daxue Nan Rd., Beijing 100081, China
}

*Corresponding author's e-mail: evezhangyan@mail.iggcas.ac.cn; 1fu@mail.iggcas.ac.cn

\begin{tabular}{l}
\hline ARTICLE INFO \\
\hline Article history: \\
Received 27 February 2016 \\
Accepted 23 August 2016 \\
Available online 7 September 2016 \\
\hline
\end{tabular}

Keywords:

Coupling mechanism;

Tele-seismic waves

Volume strain

Water level

$2011 M_{w} 9.1$ Tohoku earthquake

\begin{abstract}
According to previously reported observations, low-frequency $(\sim 0.01-500 \mathrm{~Hz})$ seismic waves can enhance permeability and alter the distribution of pore pressure, which in turn, enhance geothermal energy/oil production. To quantify the effects of low-frequency, dynamic stress stimulation on fluid flow and in-situ pore pressure variations in porous media, observations were conducted in the Fuxin well (located in a geothermal area in north-eastern China), before and after the far-field $M_{w} 9.1$ Tohoku huge earthquake. In doing so, precise measurements of earthquake-induced stress, strain, aquifer characteristics and fluid flow parameters could be obtained. We apply tidal analysis to the volumetric strain and water level data of the well. We demonstrate that the tele-seismic waves with a central frequency of $0.02 \mathrm{~Hz}$ hardly had an impact on the undrained poroelastic parameters of the aquifer, indicating that the tele-seismic waves cannot induce the disruption of the aquifer medium directly, although it can easily enhance permeability and induce the transfer of pore pressure in the aquifer. Together with the phases, the signs of the co-seismic amplitude change as well as the co-seismic and post-seismic patterns of volumetric strain and water level, we obtain the coupling mechanism of the volume strain change and the water level change: Before the earthquake, tidal volumetric strain induced the change of water level (the phase of the water level lagged behind that of the volume strain). In comparison, during the earthquake, the permeability enhanced by tele-seismic waves, water level (pore pressure) transferred from high pressure region to the Fuxin well, and induced the dilatation of volume strain (phase shifts increased sharply, indicating the change of water level caught up with that of volume strain). Finally, during the short time span after the earthquake, the water level and volumetric strain interacted with each other and changed consistently (phase shifts approach $0^{\circ}$ ).
\end{abstract}

\section{INTRODUCTION}

During geothermal exploration, injection of water into geothermal reservoirs induces thermo- and poroelastic stresses, and causes reservoir deformations. Pore pressure alters the effective stress acting on the rock, which influences rock fracture (Hassanzadegan et al., 2011). It has been repeatedly observed that low-frequency $(\sim 0.01-500 \mathrm{~Hz})$ seismic waves can enhance permeability (e.g. Brodsky et al., 2003; Elkhoury et al., 2006; Zhang et al., 2015a; Zhang et al., 2015b), and then alter the distribution of pore pressure, which enhances oil production from depleted reservoirs and contaminant extraction from groundwater aquifers. To quantify the effects of lowfrequency, dynamic-stress stimulation on fluid flow and in situ pore pressure variations in porous media, in-situ observations that enabled precise measurement of earthquake-induced stress, strain, aquifer and fluid flow parameters should be conducted.

Several recent studies show that the co-seismic change in volumetric strain measured in the far field of large earthquakes is often far greater than that predicted from static strain theory (e.g. Fu et al., 2011; Zhang et al., 2014; Zhang et al., 2015a). The underlying reason for this disparity between measurement and theory is not yet understood, mainly because of the expense in drilling and installing scientific boreholes, but it is important for the interpretation of strain data. According to the theory of linear poroelasticity (Wang, 2000), the pressure perturbation in an undrained medium is proportional to the dilatational stress imposed on it (Roeloffs, 1996). Barbour (2015) analysed records of dynamic strain and pore pressure from regional and teleseismic earthquakes at Plate Boundary Observatory stations and found robust scaling response coefficients between excess pore pressure and dynamic strain at each station that are spatially correlated.

As studied by Kilb et al (2002), in the near-field (near field: epicentral distance $\leqslant 1$ fault rupture length; far field: epicentral distance $>1000 \mathrm{~km}$ ) both the static and dynamic stresses are comparable in 


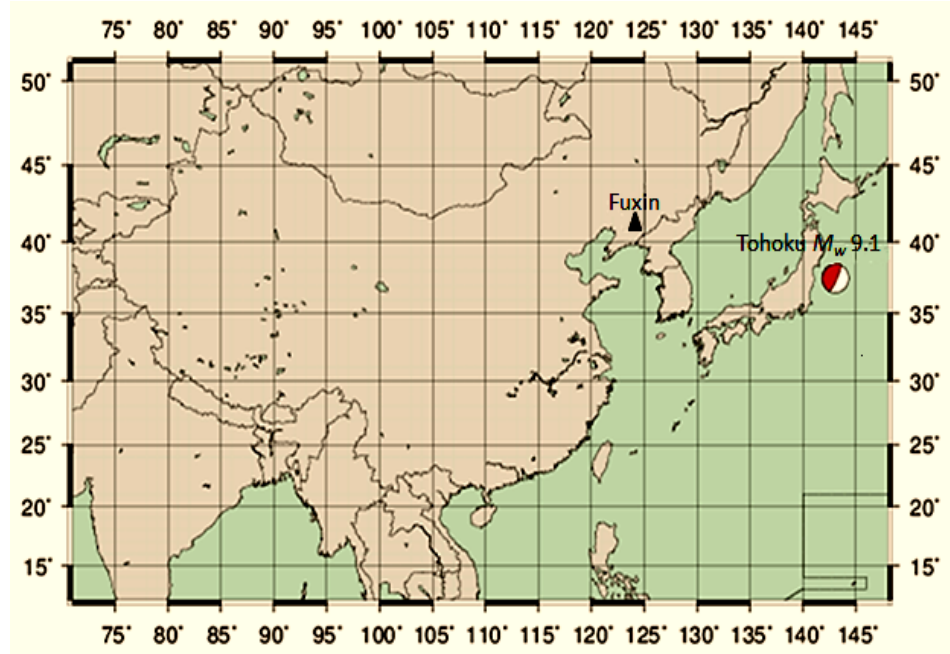

Fig. 1 Map of Southeast Asia, showing the geographic position of Fuxin well and the epicenter of the $2011 M_{w} 9.1$ Tohoku earthquake, which induced large-amplitude coseismic volume strain and water-level changes in the aquifer of the well at far fields (the epicentral distance is $1236.09 \mathrm{~km})$.

magnitude, however, in the far field, the peak dynamic stress is far greater than the static change. Thus, we may infer that the far-field variation of volume strain and water level (pore pressure) may be related to dynamic shaking by tele-seismic waves. As has been studied before, fracture clearing (unclogging) and permeability increase, induced by dynamic stress due to the propagation of tele-seismic waves, have been widely used to explain most documented farfield water level (pore pressure) changes (e.g. Brodsky et al., 2003; Elkhoury et al., 2006; Wang and Chia, 2008; Wang and Manga, 2009; Xue et al., 2013; Lai et al., 2013; Zhang et al., 2015b; Shi et al., 2014a, b; Shi et al., 2015). In addition, the size of the pressure response is generally expected to correlate with the level of seismic energy density (e.g. Wang and Chia, 2008; Zhang et al., 2015a; Lai et al., 2016). As indicated by Manga et al. (2012), in natural systems, strain amplitudes as small as $10^{-6}$ can enhance permeability.

The borehole strain metre in the Fuxin well offers an excellent opportunity to test for variation in volume strain response to the tele-seismic waves of great earthquakes and to detect the coupling mechanism between the volume strain and the water level. As previously studied, this well is extremely sensitive to great earthquakes (magnitude $>M_{S}$ 8.0) occurring in far fields (epicentral distances $>1000 \mathrm{~km}$ ) (Zhang et al., 2015a). Here we apply tidal analysis to the volumetric strain and water level data recorded in the well, before and after the $2011 M_{w} 9.1$ Tohoku earthquake. We find that tele-seismic waves with a central frequency of $0.02 \mathrm{~Hz}$ hardly had an impact on the undrained poroelastic parameters of the aquifer, suggesting that the tele-seismic waves cannot induce the disruption of the aquifer medium directly, although it can easily enhance the permeability and induce the transfer of pore pressure in the aquifer. Together with the phases, the signs of the co-seismic amplitude change as well as the co-seismic and postseismic patterns of volumetric strain and water level, we obtain the coupling mechanism of the volume strain change and the water level change. Before the earthquake, tidal volumetric strain induced the change of water level (the phase of the water level lagged behind that of the volume strain), whereas during the earthquake, the permeability enhanced by tele-seismic waves, water level (pore pressure) transferred from high pressure region to Fuxin well, and induced the dilatation of volume strain (phase shifts increased sharply, indicating the change of water level caught up with that of volume strain). Moreover, during the short time span after the earthquake, the water level and volumetric strain interacted with each other and changed consistently (phase shifts approach $0^{\circ}$ ). In addition, we also find that a dynamic energy density of $\sim 5 \times 10^{-2} \mathrm{~J} / \mathrm{m}^{3}$, which resulted from the shaking by tele-seismic waves from the far-field Tohoku earthquake (computed from broadband seismograms), could indirectly incur a dilatation stress of $\sim 0.0176 \mathrm{MPa}$ in the Fuxin well aquifer. As the Fuxin well lies in a geothermal area, this study's findings may also have implications for geothermal resource exploration.

\section{OBSERVATIONS}

The Fuxin well (Fig. 1) is located in Fuxin City, Liaoning Province, northeastern China and in the northwest Fuxin Graben Basin. The region near the well lies at a tectonic cross-section between the Yinshan and Neocathaysian structural belts. The depth of the Fuxin well is $60.74 \mathrm{~m}$. The stratigraphy at the well is as follows: $0-15 \mathrm{~m}$ is a relatively unconsolidated formation; $0-1.5 \mathrm{~m}$ is Quaternary 
Table 1 Occurrence time, epicentral distance, observed co-seismic volume strain and water level changes at the Fuxin well for the $2011 M_{w} 9.1$ Tohoku earthquake. The static co-seismic change of volume strain is calculated based on the elastic half-space dislocation model (Okada, 1992; Lin and Stein, 2004; Toda et al., 2005). The background variability of observed volume strain is computed as a standard deviation of continuous observation data during the 2.5 months before the earthquake. For the volumetric strain change, the symbol ' + ' indicates dilatation, otherwise compaction is indicated.

\begin{tabular}{ccccccc}
\hline Epicenter & $\begin{array}{c}\text { Occurrence } \\
\text { time } \\
(\text { Beijing })\end{array}$ & $\begin{array}{c}\text { Epicentral } \\
\text { distance } \\
(\mathrm{km})\end{array}$ & $\begin{array}{c}\text { Background } \\
\text { variability of } \\
\text { observed volume } \\
\text { strain }\left(10^{-9}\right)\end{array}$ & $\begin{array}{c}\text { Observed co- } \\
\text { seismic volume } \\
\text { strain change } \\
\left(10^{-9}\right)\end{array}$ & $\begin{array}{c}\text { Observed co- } \\
\text { seismic water } \\
\text { level change } \\
(\mathrm{cm})\end{array}$ & $\begin{array}{c}\text { Static co-seismic } \\
\text { change of volume } \\
\text { strain }\end{array}$ \\
\hline Tohoku & $\begin{array}{c}\left.13: 470^{-9}\right) \\
\text { 11 March 2011 }\end{array}$ & 1236.09 & 45.87 & 195.2 & 42.2 & 10.00 \\
\hline
\end{tabular}

strata and $1.5-15 \mathrm{~m}$ is formed of Cretaceous gravels, tuff and andesite. The 15-60.74 m section consists of the Liao River System monzonitic granite (AppendixFig. 1). Nearby mining activities cause frequent tremors with seismic magnitude reaching 2.5 at this well.

A TJ-2 type strain-gauge was installed at the bottom of the well to measure volume strain; its observational sensitivity $\geq 2.0 \mathrm{mV} / 10^{-8}$, resolution ratio $\leq 1 \times 10^{-9}$ and noise level $<0.1 \mathrm{mV}$. It has been working since April 1st, 2001 and records the Earth tides clearly and stably. Other down-hole digital instruments include a water level gauge and a barometric gauge, with sensitivity of $1 \mathrm{~cm} / \mathrm{mV}$ and $1 \mathrm{hPa} / \mathrm{mV}$ respectively. It should be stressed that the water level instrument used to acquire hourly data has been set to record data every minute since 2009 .

As an artesian well with the aquifer confined, the water level measurements are directly related to the changes in pore pressure. Based on the datasets, we used Mapsis software (Lu et al., 2002) to calculate the theoretical Earth tides (tidal volumetric strains). Table 1 lists some basic earthquake parameters, coseismic volume strain/water level datasets and background (pre-earthquake) volume-strain variabilities. Figure 2 (a) compares the original volume-strain, water level and Earth tide and atmospheric pressure variations observed in the Fuxin well before and after the $2011 \mathrm{Mw} 9.1$ Tohoku earthquake. We see that both the volume strain and water level show obvious co-seismic response to this far-field large earthquake. To compare the volumestrain and water level variations directly, the original datasets shown in Figure 2 (a) are corrected by removing the trend, the influence of tidal strain and atmospheric pressure using a harmonic analysis method based on the Fourier transform and wavelet decomposition (Yan et al., 2007), with the results shown in Figure 2 (b). According to the monitoring records of Fuxin station, the co-seismic volumetric strain variation induced by the $2011 M_{w} 9.1$ Tohoku earthquake has been corrected. Long-time span original water level and volume strain before and after this earthquake are shown in (Appendix-Fig. 2)

\section{CALCULATION OF THE CO-SEISMIC STATIC STRAIN CHANGE}

Using the elastic half-space dislocation model (Okada, 1992; Lin and Stein, 2004; Toda et al., 2005), we calculated the co-seismic static strain change in the Fuxin well (Fig. 3; Table 1). We see that the static volume strain changed slightly during the earthquake, much less than the observed co-seismic volume strain. This implies that the co-seismic volume strain variation cannot be attributed to the variation in the co-seismic static strain. The dynamic stress due to the huge earthquake might be used to explain the mechanism. Based on our observed data, the variation in volume strain 2004 - 2008 ranges from $408232.4 \times 10^{-9}$ to $873359.8 \times 10^{-9}$, with the amplitude change ranging from $1.0 \times 10^{-9}$ to $873359.8 \times 10^{-9}$. Using the general range of elastic moduli for some typical rocks (Liu and Tang, 1998), we set the dynamic elastic modulus to $E=90 \mathrm{GPa}$ for the bedrock (stiff granites). Using the observed volume strain change $\left(\Delta \varepsilon_{k k}\right)$, we can compute the coseismic stress change $\Delta \sigma_{k k}=E \Delta \varepsilon_{k k}=0.017568 \mathrm{MPa}$. As indicated by King et al. (1999), fracture of an impermeable fault can be induced in the far field. According to Chen and Huang (2001), the ranges in compression and tensile strength as failure limits for typical granites are 200-300 $\mathrm{MPa}$ and 4-7 MPa, respectively. Therefore, as listed in Table 1, the stress change induced by this great earthquake is far below the failure limit at which microcracks and damage occur.

\section{SEISMOGRAMS, PEAK GROUND VELOCITY (PGV) AND ENERGY DENSITY}

As indicated by Brodsky et al. (2003), only sufficient large flow velocity can result in unclogging. However, we lack observation data on induced flow velocities and high sampling rate water level records from which the flow velocity can be deduced (Wang et al., 2009). The water level records available to us are sampled at hour or minute frequencies and are not precise enough for this purpose. We have to resort to the analysis of energy density (Wang and Chia, 2008). Using a plotting software (Zhao et al., 2008), we 


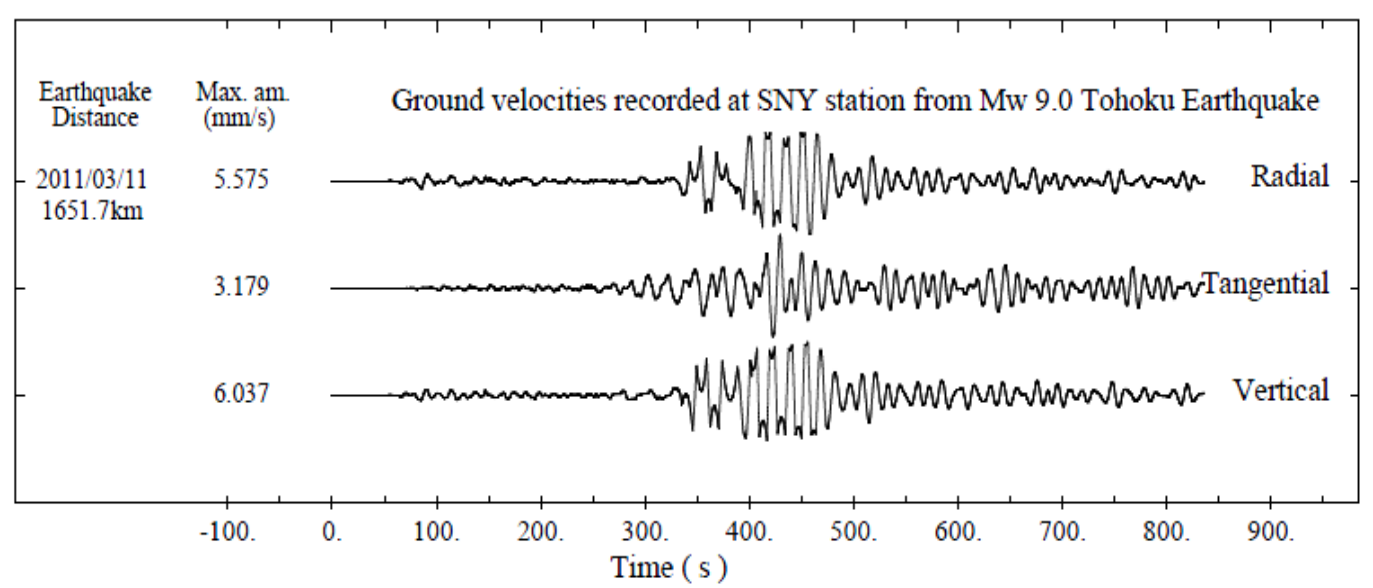

Fig. 4 Seismograms at the SNY station for the $2011 M_{w} 9.1$ Tohoku earthquake.

prepared seismograms at the SNY station (the central frequency of the tele-seismic waves received by the SNY station is $0.02 \mathrm{~Hz}$ ), as shown in Figure 4, which were used to extract certain information correlated with the co-seismic response in the Fuxin well. The distance between the station and the well is about $102.81 \mathrm{~km}$, short enough for both sites to experience similar effects from the tele-seismic waves. In addition, the geology at both sites is similar, with their main matrix rocks consisting of granites.

The first key parameter is the PGV of the $\mathrm{z}$ component. As shown in Figure 4, the z-component $\mathrm{PGV}$ is approximately $6.037 \mathrm{~mm} / \mathrm{s}$ for this huge earthquake. Therefore, the $\mathrm{z}$-component energy density can be calculated as

$\mathrm{e}=\frac{E}{V}=\frac{1 / 2 m v_{z}^{2}}{V}=\frac{1 / 2\left(\rho_{s} V\right) v_{z}^{2}}{V}=1 / 2 \rho_{s} v_{z}^{2}$

where $E$ is the seismic energy, $m$ the mass, $V$ the volume, $v_{z}$ the $\mathrm{z}$-component velocity and $\rho_{s}=$ $2.65 \mathrm{~g} / \mathrm{cm}^{3}$ is the density of the rock matrix in the well aquifer. Because of the short distance between the Fuxin well and the SNY station, the energy density $\left(4.829 \times 10^{-2} \mathrm{~J} / \mathrm{m}^{3}\right)$ could be taken as the regional value resulting from the far-field effect of the Tohoku earthquake. Based on the statistics of a global dataset from southern California, Wang and Chia (2008) show that there are sustained water level changes resulting from earthquake-enhanced permeability for an energy density between $10^{-4} \mathrm{~J} / \mathrm{m}^{3}$ and $10^{-1} \mathrm{~J} / \mathrm{m}^{3}$ in the far field $(>1000 \mathrm{~km})$. Below the threshold value, the flow velocity induced by the energy may not be large enough to promote unclogging in the aquifer. Hence, the energy density $\left(4.829 \times 10^{-2} \mathrm{~J} / \mathrm{m}^{3}\right)$ induced by the shaking of the 2011 Tohoku earthquake enhanced the permeability leading to a sustained water level increase in the far field (Fig. 2 (a), (b)).

\section{CALCULATION OF THE AMPLITUDE RATIO AND PHASE SHIFT}

Periodic changes in Earth tides cause aquifers to expand or contract, resulting in fluctuations in pore fluid pressure, leading to corresponding fluctuations of the water level in wellbores connected to confined aquifers (Hsieh et al., 1987). The amplitude and phase responses of water level to Earth tides have been used to monitor aquifer storativity and permeability, respectively (Hsieh et al., 1987; Elkhoury et al., 2006; Doan et al., 2006; Xue et al., 2013). In a confined system small phase lags result from high permeability, whereas large phase lags result from low permeability. The amplitude response is primarily a measure of specific storage.

Cooper et al. (1965) showed that the steady fluctuation of water level in a well occurs at the same frequency as the harmonic pressure head disturbance in the aquifer. However, the amplitude of the response is generally different from that of the disturbance and there is also a shift in phase. Hsieh et al. (1987) described the pressure head disturbance and water level response by

$h_{f}=h_{o} \exp (i \omega t)$

$x=x_{0} \exp (i \omega t)$

respectively, where $h_{f}$ is the fluctuating pressure head in the aquifer; $h_{o}$ is the complex amplitude of pressure head fluctuation; $x$ is the displacement of the water level from the static position; $x_{o}$ is the complex amplitude of the water level fluctuation; $i=(-1)^{1 / 2}$; $t$ indicates time; $\omega=2 \pi / \tau$ is the frequency of fluctuation; $\tau$ is the period of fluctuation.

Complex notation is used in (1) and (2) to facilitate the theoretical development below. However, it is understood that we are interested in only the real parts of $h_{f}$ and $x$. The amplitude response $A$ is defined as the ratio between the amplitude of the water level fluctuation and that of the pressure head fluctuation. In terms of $x_{o}$ and $h_{o}, A$ can be expressed as

$A=\left|x_{o} / h_{o}\right|$

The phase shift is defined as 

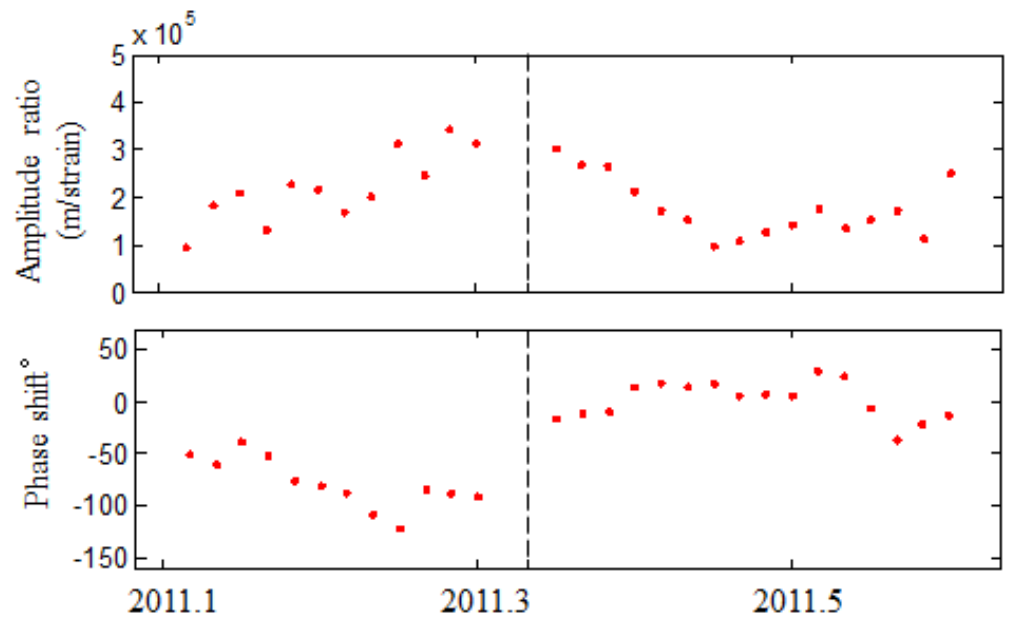

(Jan. 6, 2011-May 25, 2011)

Fig. 5 Amplitude and phase responses over time at the frequency of $\mathrm{M}_{2}$ wave from the Fuxin well before and after the $2011 M_{w} 9.1$ Tohoku earthquake. The amplitude response is the amplitude ratio of water level over volume strain. The vertical dashed lines indicate the start time of the earthquake (Beijing time).

$\eta=\arg \left(x_{o} / h_{o}\right)$

where $\arg (z)$ is the argument of the complex number $z$. The phase shift can be thought of as being $2 \pi t_{p} / \tau$, where $t_{p}$ is the time lag from the moment the water level fluctuation reaches a peak to the moment the pressure head fluctuation reaches a peak.

The well response depends on the flow of water through the porous medium and therefore is sensitive to the aquifer transmissivity and storage. Transmissivity is the rate of water transmission through a unit width of aquifer under a unit hydraulic gradient and is directly proportional to permeability. Storage coefficient is the volume of water released from storage per unit decline in hydraulic head in the aquifer. Additional factors of the response in the most general case also include the well geometry, the period of oscillation and inertial effects. The inertial effects are negligible for long periods of the Earth tides (Cooper et al., 1965). The other two factors are independently well constrained. Thus, the amplitude $A$ and phase $\eta$ responses for the long periods of tidal oscillations are (Hsieh et al., 1987):

$A=\left(E^{2}+F^{2}\right)^{-1 / 2}$

$\eta=-\tan ^{-1}(F / E)$

where

$E \approx 1-\left(\omega r_{c}^{2} / 2 T\right) \operatorname{Kei}(\alpha), F \approx\left(\omega r_{c}^{2} / 2 T\right) \operatorname{Ker}(\alpha)$,

$$
\alpha=(\omega S / T)^{1 / 2} r_{w}
$$

and $T$ is the transmissivity, $S$ is the dimensionless storage coefficient, Ker and Kei are the zero-order Kelvin functions, $r_{w}$ is the radius of the well $(7.5 \mathrm{~cm}$ for Fuxin well), $r_{c}$ is the inner radius of the casing $(6.5 \mathrm{~cm}$ for Fuxin well) and $\omega$ is the frequency of the tide.
The most commonly analysed phase is $\mathrm{M}_{2}$ because of its large amplitude and relatively low contamination by barometric pressure or diurnal temperature fluctuations (Hsieh et al., 1987; Rojstaczer and Agnew, 1989; Doan et al., 2006). In this work, we also focused on the $\mathrm{M}_{2}$ phase (period $745.2 \mathrm{~min}$ ). We calculated the amplitude ratio and phase shift between the water level and the volumetric strain based on the cross-correlation method (e.g., Lai et al., 2011; Zhang et al., 2015a), with a moving time window of 30 days and a running step of 3 days (Fig. 5).

As indicated in Figure 5 and Table 2, the phase shifts increased after the 2011 Tohoku earthquake, implying a permeability increase. Hence, the coseismic water-level change mostly occurred as a result of the enhanced permeability induced by the shaking from the tele-seismic waves. According to Hsieh et al. (1987), for a homogeneous, isotropic, laterally extensive and confined aquifer, the phase shifts between Earth tides (volumetric strain) and water level are assumed to be caused by the time required for water flowing into and out of the well. In such a case, the water-table drainage effect is ignored, and the resulting phase shift should always be negative. In other words, a phase shift increase (e.g. from $-5^{\circ}$ to $-1^{\circ}$ ) implies an increase in transmissivity or permeability (Hsieh et al., 1987; Elkhoury et al., 2006). However, in this paper, positive phase shifts were observed after the earthquake, which might be attributed to errors. We calculated the standard deviation of the pre-earthquake phase shift to be 23.6588. Thus, the phase shifts could be $0^{\circ}$ after the earthquake, indicating that the variation in water level caught up with that of the volumetric strain and then changed similarly and consistently. 
Table 2 Co-seismic phases and amplitude responses from the Fuxin well for the $2011 M_{w} 9.1$ Tohoku earthquake.

\begin{tabular}{|c|c|c|c|c|c|c|c|}
\hline $\begin{array}{l}\text { Pre-earthquake } \\
\text { phase shift }{ }^{\circ}\end{array}$ & $\begin{array}{c}\text { Post- } \\
\text { earthquake } \\
\text { phase shift }{ }^{\circ}\end{array}$ & $\begin{array}{c}\text { Background } \\
\text { phase shift } \\
\text { variability }{ }^{\circ}\end{array}$ & $\begin{array}{l}\text { Coseismic } \\
\text { phase shift } \\
\text { change }{ }^{\circ}\end{array}$ & $\begin{array}{l}\text { Pre-earthquake } \\
\text { amplitude ratio } \\
/ 10^{5}(\mathrm{~m} / \text { strain })\end{array}$ & $\begin{array}{l}\text { Post-earthquake } \\
\text { amplitude ratio } \\
/ 10^{5}(\mathrm{~m} / \text { strain })\end{array}$ & $\begin{array}{c}\text { Background } \\
\text { amplitude ratio } \\
\text { variability } \\
/ 10^{5}(\mathrm{~m} / \text { strain })\end{array}$ & $\begin{array}{c}\text { Coseismic } \\
\text { amplitude ratio } \\
\text { change } \\
/ 10^{5}(\mathrm{~m} / \text { strain })\end{array}$ \\
\hline-87.6006 & -12.0773 & 23.6588 & 75.5233 & 3.023 & 2.801 & 0.715 & -0.222 \\
\hline
\end{tabular}

Table 2 lists the co-seismic phase shift and amplitude ratio responses. The phase response means phase shifts between volumetric strain and water level, where the symbol ' - ' indicates a lag of water level behind volume strain. The pre-/post-earthquake values are the respective average values of three pre/post-earthquake points measured within 15 days of the earthquake. The background variabilities are the standard deviations of the pre-earthquake phase shifts and amplitude ratios. The co-seismic variations of phase shift / amplitude ratio are obtained by subtracting the pre-earthquake values from the postearthquake values.

Before the earthquake, water level fluctuation in the Fuxin well had a negative phase shift as a result of the delay in groundwater flow to the well, driven by the tidal volumetric strain of the aquifer. In comparison, following the earthquake, the phase of the water level fluctuations caught up with that of the volumetric strain, suggesting that the co-seismic change in strain may reflect the co-seismic change in pore pressure (water level) in the aquifer. After the earthquake, the water level might still maintain a dynamic state, that is, continues to flow into the well or flow out of the well to recover and influence the volume strain. Meanwhile, the volume strain induced the change of water level in the manner of tidal strain. Thus, during a short time span after the earthquake, the phase shifts between the water level and the volume strain approached zero (Fig. 5), indicating that the water level and volumetric strain interacted with each other and changed consistently.

\section{CALCULATION OF CONTINUOUS BK (B: SKEMPTON'S COEFFICIENT; $K_{U}$ : UNDRAINED BULK MODULUS) AND TRANSMISSIVITY}

In the near field, where the co-seismic static strain is large and thus the measured strain is consistent with that predicted from an elastic model (Johnston and Linde, 2002). However, in the far field, the situation is different. As shown in Table 1, the coseismic increase in the volumetric strain measured is far greater than that predicted from static strain theory. The underlying reason for this disparity is not yet understood. As analysed above, the co-seismic change in strain may reflect the co-seismic change in pore pressure (water level) in the aquifer. Thus, poroelastic theory can be used to clarify this mechanism.

For the loading of Earth tides, the periods of diurnal and semi-diurnal waves are relatively shorter compared with the time scale of the discharge and recharge time of groundwater, which could be regarded as an undrained condition (Yan, 2008). Therefore, we could evaluate the undrained parameters of the aquifer based on poroelastic-theory using the loading of the $\mathrm{M}_{2}$ wave (Yan, 2008; Zhang et al., 2009; Zhang and Huang, 2011; Shi et al., 2013).

In a confined reservoir, for the linearly poroelastic media, the amplitude of pore pressure change in the aquifer, $\Delta p$, may be related to the amplitude of volumetric strain change, $\Delta \varepsilon$, by the following relationship (Doan et al., 2006):

$\Delta p=-\frac{B \Delta \sigma_{k k}}{3}=-B K_{u} \Delta \varepsilon$,

where $K_{u}$ is the undrained bulk modulus, and $B$ is the Skempton coefficient. Equation (8) indicates that in the undrained condition, the change in fluid pressure $\Delta p$ is proportional to the change in volume strain $\Delta \varepsilon$. Using equation (8), we obtain the following

$\Delta h=\frac{-B K_{u} \Delta \varepsilon}{\rho g}$,

where $\rho$ is the density of water, $g$ is the gravitational acceleration, and $\Delta h$ is the change in pressure head in the aquifer. Using equations (9) and (3), we derive the following:

$A=\left|x_{o} / h_{o}\right|=\left|x_{o} /\left(\frac{B K_{u} \varepsilon_{0}}{\rho g}\right)\right|=\left|x_{o} / \varepsilon_{0}\right| /\left(\frac{B K_{u}}{\rho g}\right)$,

where $\varepsilon_{0}$ is the change in mean strain (volumetric strain). Assuming the storage coefficient $S=10^{-4}$, this is a typical value and the most often used for aquifers as it is not sensitive to changes in phase and amplitude (e.g. Doan et al., 2006; Lai et al., 2011). On the basis of equations (5), (6), (7) and (10), and substituting the measured phase $\eta$ and the amplitude response ratio $\left|x_{o} / \varepsilon_{0}\right|$ (Fig. 5), we can derive $B K_{u}$ (B: Skempton's coefficient; $K_{u}$ : undrained bulk modulus) and the transmissivity $\mathrm{T}$ (Fig. 6). In accordance with the calculation of amplitude ratio and phase shift, $B K_{u}$ and the transmissivity $\mathrm{T}$ are also calculated with a moving time window of 30 days and a running step of 3 days (Fig. 6).

Table 3 lists the $B K_{U}$ and transmissivity values obtained in this study. As can be seen, the initial $B K_{U} /$ transmissivity values are the average values at three pre-earthquake points, measured within 15 days of the earthquake. The background variables are the standard deviations of the pre-earthquake $B K_{U}$ and transmissivity values. The co-seismic $B K_{U} /$ transmissivity changes are obtained by 


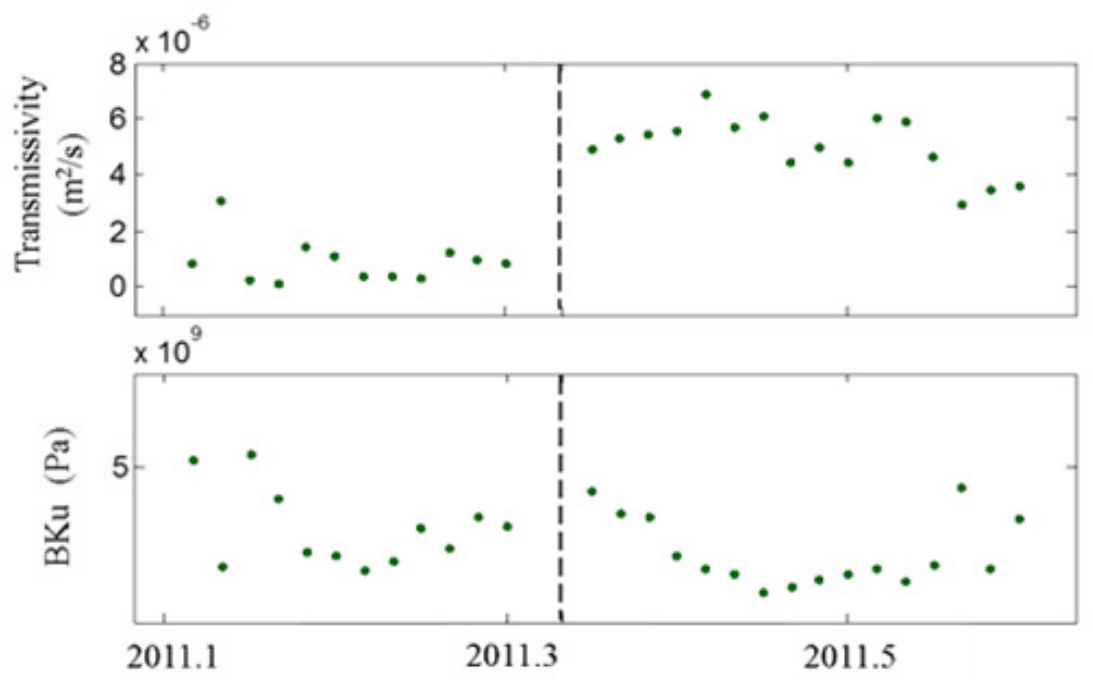

Fig. 6 Transmissivity and $B K_{U}$ over time from the Fuxin well before and after the $2011 M_{w} 9.1$ Tohoku earthquake. The vertical dashed lines indicate the start time of the earthquake (Beijing time).

Table 3 Initial, background and co-seismic change of $B K_{u}$ and transmissivity from the Fuxin well for the 2011 $M_{w} 9.1$ Tohoku earthquake.

\begin{tabular}{cccccc}
\hline $\begin{array}{c}\text { Initial } \\
B K_{U} / G P a\end{array}$ & $\begin{array}{c}\text { Background } \\
B K_{U} \\
\text { variability } / \mathrm{GPa} a\end{array}$ & $\begin{array}{c}\text { Coseismic } \mathrm{BK} K_{U} \\
\text { change } / \mathrm{GPa}\end{array}$ & $\begin{array}{c}\text { Initial } \\
\text { transmissivity } /\left(\mathrm{m}^{2} / \mathrm{s}\right)\end{array}$ & $\begin{array}{c}\text { Background } \\
\text { transmissivity } \\
\text { variability } /\left(\mathrm{m}^{2} / \mathrm{s}\right)\end{array}$ & $\begin{array}{c}\text { Coseismic } \\
\text { transmissivity } \\
\text { change } /\left(\mathrm{m}^{2} / \mathrm{s}\right)\end{array}$ \\
\hline 2.9622 & 0.8125 & 0.7543 & $1.0519 \times 10^{-6}$ & $7.7507 \times 10^{-7}$ & $4.1958 \times 10^{-6}$ \\
\hline
\end{tabular}

Table 4 Pre-seismic $B K_{u}$, the converted co-seismic change of volumetric strain from the co-seismic change in water level, and the observed co-seismic change of volumetric strain.

\begin{tabular}{cccc}
\hline Earthquake & $\begin{array}{c}\text { Pre-earthquake } \\
B K_{U}(\mathrm{GPa})\end{array}$ & $\begin{array}{c}\text { Converted co-seismic change of } \\
\text { volumetric strain from co-seismic } \\
\text { change in water level }\left(10^{-9}\right)\end{array}$ & $\begin{array}{c}\text { Co-seismic change of } \\
\text { volumetric strain }\left(10^{-9}\right)\end{array}$ \\
\hline $\begin{array}{c}2011 M_{w} 9.1 \\
\text { Tohoku }\end{array}$ & 2.96 & 1397.16 & 195.2 \\
\hline
\end{tabular}

subtracting the initial $B K_{U} /$ transmissivity from the average values from the three post-earthquake points within 15 days of the earthquake. Upon calculation, the $B K_{U}$ values did not change; however, the transmissivity increased obviously after the earthquake, indicating that the low frequency $(0.02 \mathrm{~Hz})$ tele-seismic waves hardly had any impact on the variation of the undrained poroelastic parameters of the aquifer. This finding indicates that the tele-seismic waves cannot induce the disruption of the aquifer medium directly; however, they can easily enhance the permeability and induce the transfer of pore pressure in the aquifer. In addition, the coseismic permeability increased markedly because of the large energy induced by the tele-seismic waves of the $2011 M_{w} 9.1$ Tohoku earthquake.

\section{COMPARISON OF VOLUME STRAIN AND WATER LEVEL}

Assuming the same $B K_{u}$ as the initial value for the co-seismic change, we may convert the co-seismic change of water level during the earthquake to the corresponding co-seismic change in volumetric strain with equation (9). The converted value is listed in Table 4. As seen in the table, the converted value shows the same sign as the observed co-seismic change in volumetric strain. The difference (within a ratio factor of 7) between the converted and the observed volumetric strain may be attributed to the unaccounted factors such as ocean tides or energy attenuations.

Finally, to further support the above hypothesis, we compare in Figure 7 the time history of the volumetric strain with that of the water level (pore pressure) in the Fuxin well. In order to facilitate the comparison, we normalize the time series by its maximal value in the first 20 days following the earthquake. Figure 7 shows that the time history of the change in volumetric strain after the earthquake closely resembles that of the change in water level. Furthermore, from Figure 7, we can see that the water level (pore pressure) even changed ahead of the volume strain during the first 5 days after the earthquake. This similarity in change pattern, together 
with the post-seismic similarity between the phase of the tidal response of water level and that in the volumetric strain (Fig. 5), suggests that the co-seismic volumetric strain in the Fuxin well may primarily be produced by the co-seismic change in pore pressure (water level). As discussed above, after the earthquake, the water level may still maintain a dynamic state (i.e. continue to flow into the well or flow out of the well to recover) and influence the volume strain. Meanwhile, the volume strain induced the change of water level in the manner of tidal strain. Thus, during a short time span after the earthquake the phase shifts between the water level and the volume strain approached zero (Fig. 5), thereby indicating that the water level and volumetric strain interacted with each other and changed consistently (Fig. 7).

\section{CONCLUSION}

In this article, we applied tidal analysis to investigate the volumetric strain and water level documented in the Fuxin well before and after the large $M_{w} 9.1$ Tohoku earthquake. We find that teleseismic waves with a central frequency of $0.02 \mathrm{~Hz}$ cannot induce the disruption of the aquifer medium directly, although they can easily enhance the permeability and induce the transfer of pore pressure in the aquifer. Together with the phases, the signs of the co-seismic amplitude change and the co-seismic and post-seismic patterns of volumetric strain and water level, we obtain the coupling mechanism of the volume strain change and the water level change. Before the earthquake, tidal volumetric strain induced the change of water level, that is, the phase of the water level lagged behind that of the volume strain. Moreover, during the earthquake, the permeability enhanced by tele-seismic waves, water level (pore pressure) transferred from high pressure region to the Fuxin well and induced the dilatation of volume strain (phase shifts increased sharply, indicating the change of water level caught up with that of volume strain). Finally, during a short time span after the earthquake, the phase shifts between the water level and the volume strain approached zero, indicating that the water level and volumetric strain interact with each other and change consistently. In addition, we also found that a dynamic energy density of $\sim 5 \times$ $10^{-2} \mathrm{~J} / \mathrm{m}^{3}$, which resulted from the shaking of the teleseismic waves from the far-field Tohoku earthquake (computed from broadband seismograms), could indirectly generate a dilatation stress of $\sim 0.0176 \mathrm{MPa}$ in the Fuxin well aquifer. Given that the Fuxin well lies in a geothermal area, the results of this study may also have some implications for geothermal resource exploration.

\section{ACKNOWLEDGMENTS}

We are deeply grateful to professor Chi-yuen Wang and Rui Yan for their suggestions and insightful discussions and thank two anonymous reviewers for their good suggestions. This research was supported by the Strategic Leading Science and Technology
Programme (Class B) of the Chinese Academy of Sciences (Grant No. XDB10010400), the National Natural Science Foundation of China (Grant No. 41604035), and the China Postdoctoral Science Foundation (Grant No. 2015M570142 and 2016T90129).

\section{APPENDIX}

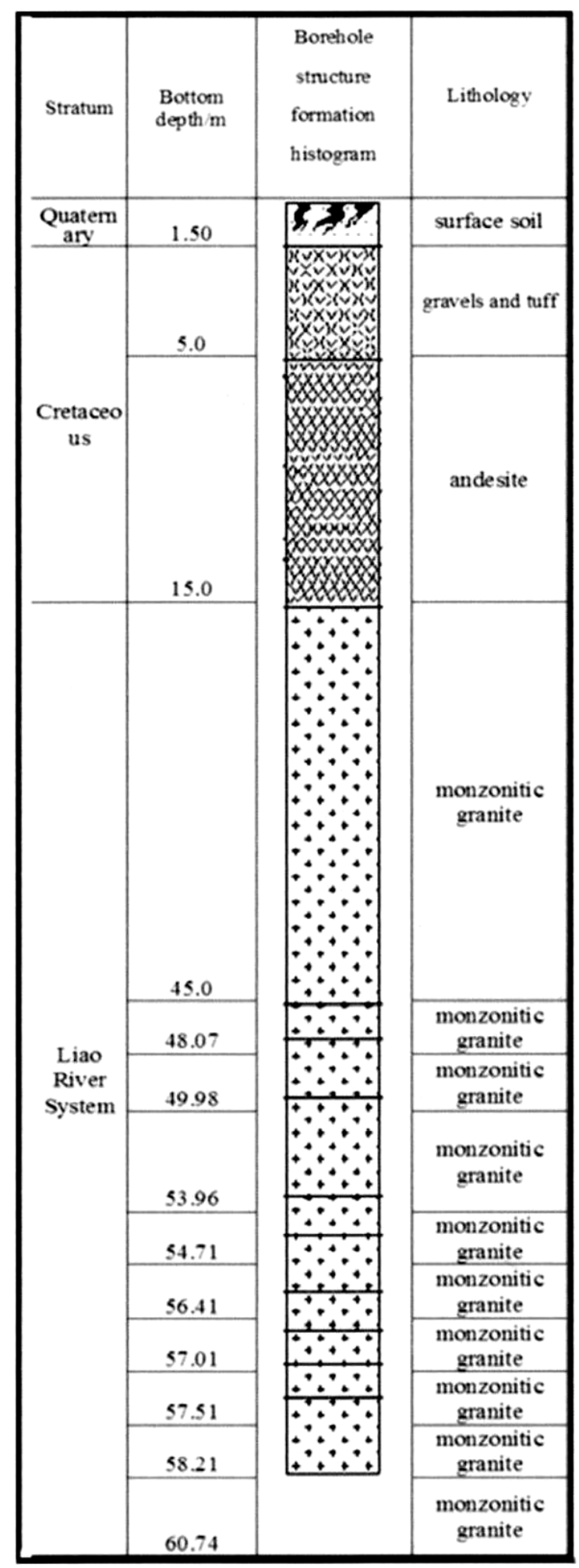

Fig. 1 Lithologic log of the Fuxin well from Seismic monitoring records of China. 

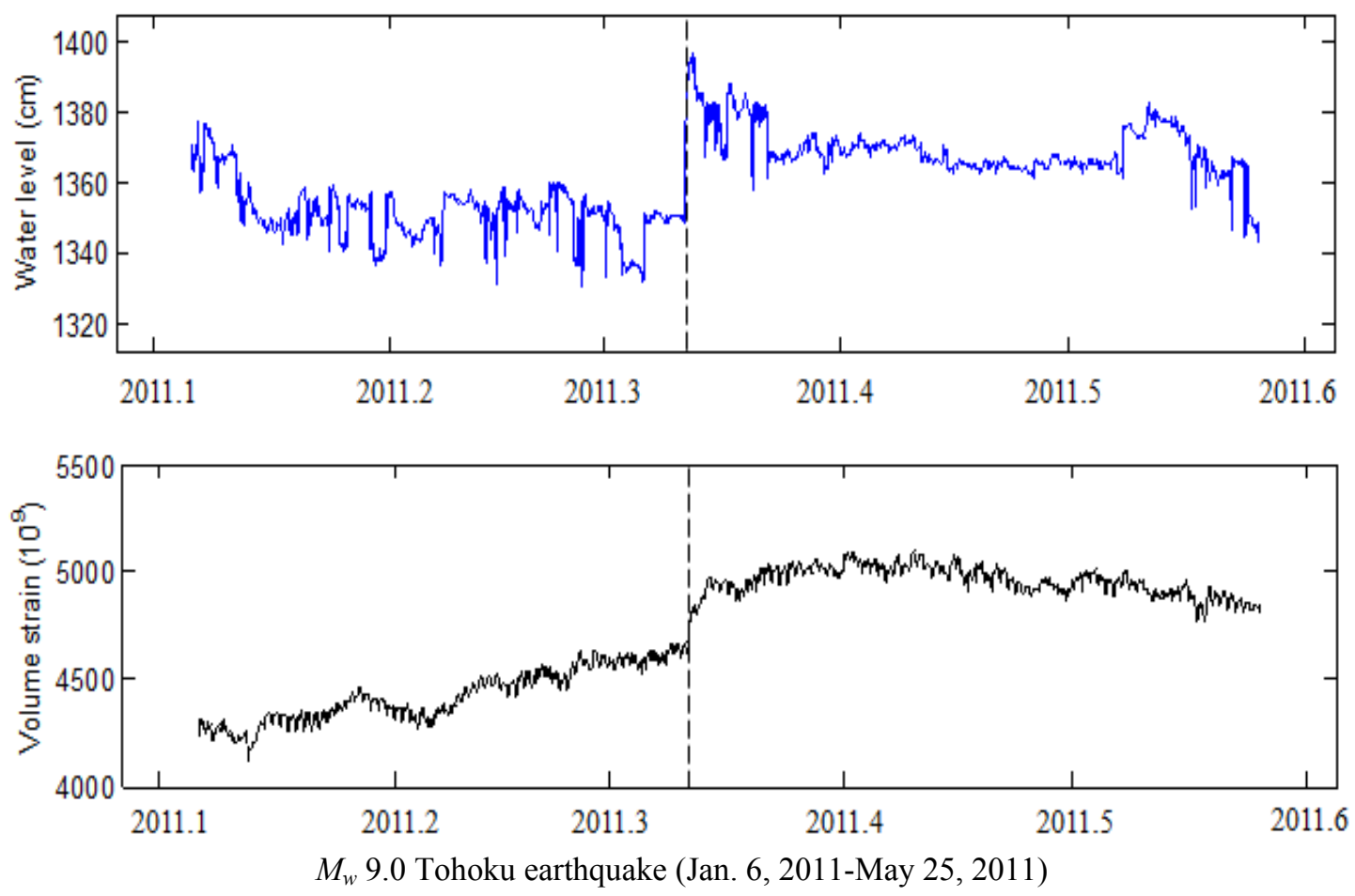

Fig. 2 Original water level and volume strain at the Fuxin well for the $2011 M_{w} 9.1$ Tohoku earthquake. The vertical dashed lines indicate the start time of the earthquake (Beijing time). (*The coseismic volume strain has been corrected according to the observation records of the Fuxin station).

\section{REFERENCES}

Brodsky, E.E., Roeloffs, E., Woodcock, D., Gall, I. and Manga, M.: 2003, A mechanism for sustained groundwater pressure changes induced by distant earthquake. J. Geophys. Res., 108, B8, 2390. DOI: 1029/2002JB002321

Barbour, A.J.: 2015, Pore pressure sensitivities to dynamic strains: Observations in active tectonic regions. J. Geophys. Res. Solid Earth, 120, 8, 5863-58883.

DOI: $10.1002 / 2015 J B 012201$

Chen, Y. and Huang, T.F.: 2001, Rock Physics. Beijing University Press, Beijing, China, 9 pp, (in Chinese).

Cooper, H.H., Bredhoeft, J.D., Papadopulos, I.S. and Bennnett, R.R.: 1965, The response of aquifer-well systems to seismic waves, J. Geophys. Res., 70, 16, 3915-3926. DOI: 10.1029/JZ070i016p03915

Doan, M.L., Brodsky, E.E., Prioul, R. and Signer, C.: 2006, Tidal analysis of borehole pressure- A tutorial. Schlumberger Research Report.

Elkhoury, J.E., Brodsky, E.E. and Agnew, D.C.: 2006, Seismic waves increase permeability. Nature, 411, 1135-1138. DOI: 10.1038/nature04798

Fu, G., Shen, X., Yoichi, F., Gao, S., and Yoshii, S.: 2011, Co-seismic strain changes of Wenchuan $M_{w} 7.9$ earthquake recorded by borehole strainmeters on Tibetan plateau. Geodesy and Geodynamics, 2, 3, 4249. DOI: $10.3724 /$ SPJ.1246.2011.0042

Hsieh, P.A., Bredehoeft, J.D. and Farr, J.M.: 1987, Determination of aquifer transmissivity from Earth tide analysis. Water. Resour. Res., 23, 10, 1824-1832. DOI: 10.1029/WR023i010p01824

Hassanzadegan, A., Blöcher, G., Zimmermann, G., Milsch, H. and Moeck, I.: 2011, Induced stress in a geothermal doublet system. Proceedings, Thirty-Sixth Workshop on Geothermal Reservoir Engineering, Stanford University, Stanford, California, January 31 February 2, 2011.

Johnston, M.J.S. and Linde, A.T.: 2002, Implications of crustal strain during conventional, slow, and silent earthquakes. In International Handbook of Earthquake and Engineering Seismology, 81A, Academic Press, New York, 589-605.

King, C.Y., Azuma, S., Igarashi, G., Ohno, M., Saito, H. and Wakita, H.: 1999, Earthquake-related water-level changes at 16 closely clustered wells in Tono, central Japan. J. Geophys. Res., 104, B6, 13073-13082. DOI: $10.1029 / 1999 J B 900080$

Kilb, D., Gomberg, J. and Bodin, P.: 2002, Aftershock triggering by complete Coulomb stress changes. J. Geophys. Res., 107, B4, ESE 2-1-ESE2-14.

DOI: 10.1029/2001JB000202

Lin, J. and Stein, R.S.: 2004, Stress triggering in thrust and subduction earthquakes and stress interaction between the southern San Andreas and nearby thrust and strikeslip faults. J. Geophys. Res., 109, B2. DOI: 10.1029/2003JB002607

Liu, Y.R. and Tang, H.M.: 1998, Rock Mass Mechanics. Press of China University of Geosciences, Beijing, China, $112 \mathrm{pp}$.

Lu, Y.Z., Li, S.L., Deng, Z.H., Pan, H.W., Che, S. and Li, Y.L.: 2002, Seismology analysis and prediction system based on GIS (MapSIS Software). Chengdu Map Press, Chengdu, China, 232 pp.

Lai, G.J., Ge, H.K., Xue, L., Brodsky, E.E., Huang, F.Q. and Wang, W.W.: 2013, Tidal response variation and recovery following the Wenchuan earthquake from 
water level data of multiple wells in the nearfield. Tectonophysics, 610, 12, 1-12.

DOI: $10.1016 / j$.tecto.2013.08.039

Lai, G.J., Huang, F.Q. and Ge, H.K.: 2011, Apparent permeability variation of underground water aquifer induced by an earthquake: A case of the Zhouzhi well and the 2008 Wenchuan earthquake. Earthq Sci., 24, 5, 437-445. DOI: 10.1007/s11589-011-0806-2

Lai, G.J., Jiang, C.S., Han, L.B., Sheng, S.Z., and Ma,Y.C.: 2016, Co-seismic water level changes in response to multiple large earthquakes at the LGH well in Sichuan, China. Tectonophysics, 679, 211-217. DOI: $10.1016 /$ j.tecto.2016.04.047

Manga, M., Beresnev, I., Brodsky, E.E., Elkhoury, J.E., Elsworth, D., Ingebritsen, S., Mays, D.C. and Wang, C.Y.: 2012, Changes in permeability by transient stresses: Field observations, experiments and mechanisms. Rev. Geophys., 50, RG2004. DOI: $10.1029 / 2011 \mathrm{RG} 000382$

Okada, Y.: 1992, Internal deformation due to shear and tensile faults in a half-space. Bull. Seismol. Soc. Am., 82, 2, 1018-1040.

Roeloffs, E.A.: 1996, Poroelastic techniques in the study of earthquakes-related hydrologic phenomena. Adv. Geophys., 37, 135-195. DOI: $10.1016 / \mathrm{S} 0065-2687(08) 60270-8$

Rojstaczer, S. and Agnew, D.C.: 1989, The influence of formation material properties on the response of water levels in wells to Earth tides and atmospheric loading. J. Geophys. Res., 94, B9, 12403-12411. DOI: 10.1029/JB094iB09p12403

Shi, Z.M., Wang, G.C. and Liu, C.L.: 2013, Co-seismic groundwater level changes induced by the May 12, 2008 Wenchuan earthquake in the near field. Pure Appl. Geophys., 170, 11, 1773-1783.

DOI: $10.1007 / \mathrm{s} 00024-012-0606-1$

Shi, Z.M. and Wang, G.C.: 2014(a), Hydrological response to multiple large distant earthquakes in the Mile well, China. J. Geophys. Res., Earth Surf, 119, 11, 24482459. DOI: $10.1002 / 2014 J F 003184$

Shi, Z.M., Wang, G.C., Wang, C.Y., Manga, M. and Liu, C.L.: 2014(b), Comparison of hydrological responses to the Wenchuan and Lushan earthquakes. Earth Planet. Sci. Lett., 391, 193-200. DOI: 10.1016/j.eps1.2014.01.048

Shi, Z.M., Wang, G.C., Manga, M. and Wang, C.Y.: 2015, Mechanism of co-seismic water level change following four great earthquakes - insights from coseismic responses throughout the Chinese mainland. Earth Planet. Sci. Lett., 430, 66-74. DOI: $10.1016 /$ j.epsl.2015.08.012

Toda, S., Stein, R.S., Richards-Dinger, K. and Bozkurt, S.: 2005, Forecasting the evolution of seismicity in southern California: Animations built on earthquake stress transfer. J. Geophys. Res., 110, B05S16. DOI: $10.1029 / 2004 J B 003415$

Wang, H.F.: 2000, Theory of linear poroelasticity with application to geomechanics and hydrogeology. Princeton University Press, Princeton, 62 pp.
Wang, C.Y., Chia, Y., Wang, P. L. and Dreger, D.: 2009, Role of $\mathrm{S}$ waves and Love waves in co-seismic permeability enhancement. Geophys. Res. Lett., 36, L09404. DOI: 10.1029/2009GL037330

Wang, C.Y. and Chia, Y.: 2008, Mechanism of water level changes during earthquakes: Near field versus intermediate field. Geophys. Res. Lett., 35, L12402. DOI: $10.1029 / 2008$ GL034227

Wang, C.Y. and Manga, M.: 2009, Earthquakes and Water. Lecture Notes in Earth Sciences. Springer Press, Berlin, 114, 18-24. DOI: 10.1007/978-3-642-00810-8

Xue, L., Li, H.B., Brodsky, E.E., Xu, Z.Q., Kano, Y., Wang, H., Mori, J.J., Si, J.L., Pei, J.L., Zhang, W., Yang, G., Sun, Z.M. and Huang, Y.: 2013, Continuous permeability measurements record healing inside the Wenchuan Earthquake Fault Zone. Science, 340, 6140, 1555-1559. DOI: 10.1126/science. 1237237

Yan, R., Huang, F.Q. and Chen, Y.: 2007, Application of wavelet decomposition to remove barometric and tidal response in borehole water level. Earthquake Research in China, 23, 2, 204-210, (in Chinese).

Yan, R.: 2008, Study of several influence factor of well water level change: M.S. thesis, Institute of earthquake prediction, China earthquake administration, (in Chinese).

Zhang, Y., and Huang, F.Q.: 2011, Mechanism of different coseismic water-level changes in wells with similar epicentral distances of intermediate field. Bull. Seismol. Soc. Am., 101, 4, 1531-1541. DOI: $10.1785 / 0120100104$

Zhang, Y., Huang, F. Q. and Lai, G.: 2009, Research on Skempton's coefficient B based on the observation of groundwater of Changping station. Earthq. Sci., 22, 6, 631-638. DOI: 10.1007/s11589-009-0631-z

Zhang, B., Liu, Y.W. and Wang, C.Y.: 2014, Response of volumetric strain and groundwater level to earthquakes. 2014 AGU Session, 2583: Advances in Site Response.

Zhang, Y., Fu, L.Y., Huang, F.Q. and Chen, X.Z.: 2015a, Co-seismic water-level changes in a well induced by teleseismic waves from three large earthquakes. Tectonophysics, 651-652, 232-241.

DOI: $10.1016 /$ j.tecto.2015.02.027

Zhang, Y., Fu, L.Y., Huang, F.Q. and Chen, X.Z.: 2015b, Permeability enhancement in the aquifer of Fuxin well in geothermal area of northeastern China induced by low-frequency teleseismic waves of the $2011 M_{W} 9.0$ Tohoku earthquake. Acta Geodyn. Geomater., 12, 1(177), 29-38. DOI: 10.13168/AGG.2015.0007

Zhao, L.F., Xie, X.B., Wang, W.M. and Yao, Z.X.: 2008, Regional seismic characteristics of the 9 October 2006 North Korean nuclear test. Bull. Seismol. Soc. Am., 98, 6, 2571-2589. DOI: 10.1785/0120080128 
$M_{w} 9.1$ Tohoku earthquake
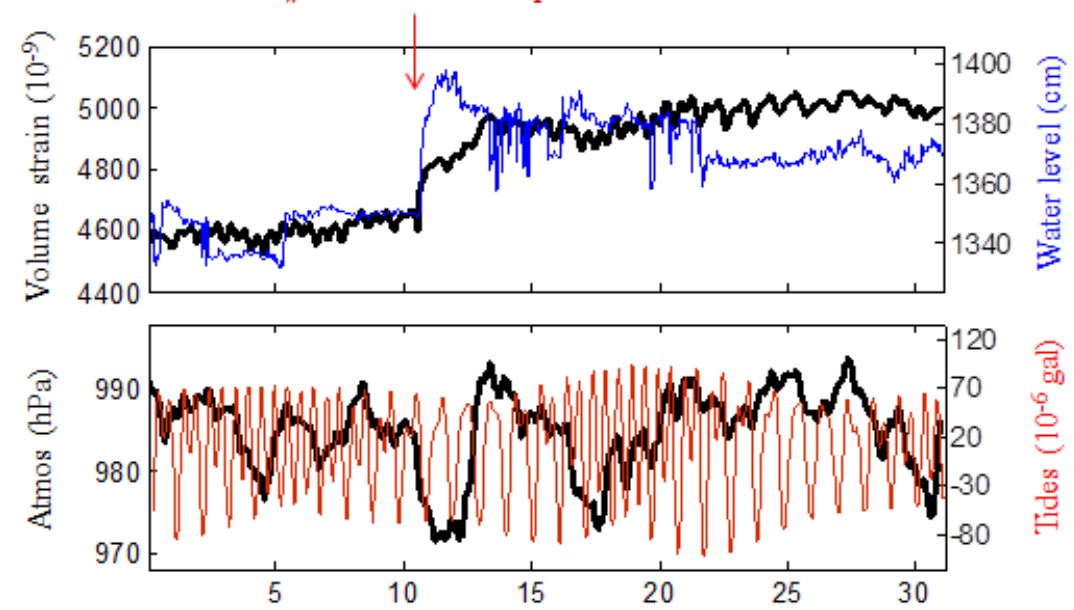

(Mar. 1, 2011-Mar. 31, 2011)

(a)

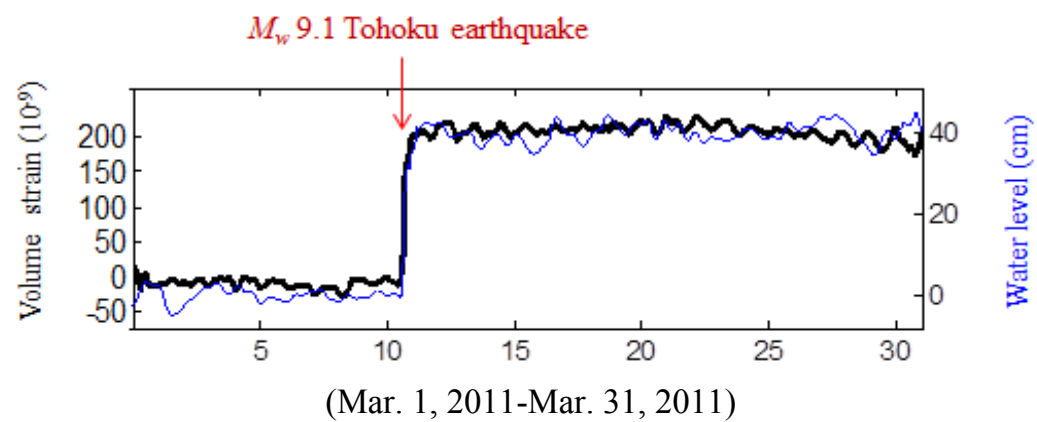

(b)

Fig. 2 (a) Original volume-strain (black thick line), water-level (blue thin line), solid-tide (red thin line), and atmospheric-pressure (black thick line) variations versus time from the Fuxin well before and after the $2011 M_{w} 9.1$ Tohoku earthquake. The arrow indicates the occurrence time of the earthquake; (b) Corrected volume-strain (black thick line) and water-level (blue thin line) variations versus time for the Fuxin well.

Fig. 7 Comparison of the first 20 days of the normalized volumetric strain response (black) to the Tohoku earthquake and with the normalized water level (pore pressure) response (red).

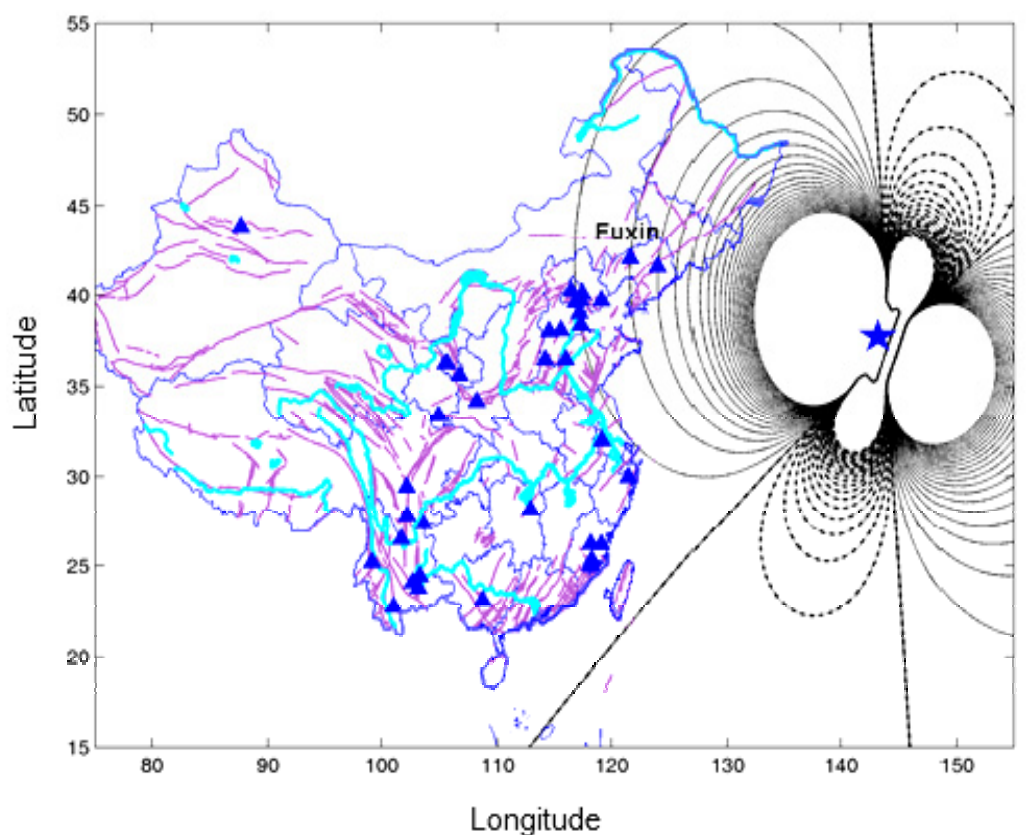

Fig. 3 The spatial distribution of the static volume-strain changes for the $2011 M_{w} 9.1$ Tohoku earthquake, calculated using the elastic half-space dislocation model (Okada, 1992; Lin and Stein, 2004; Toda et al., 2005). trend, $203^{\circ}$; angle of inclination, $10^{\circ}$; angle of slide, $88^{\circ}$; depth $20 \mathrm{~km}$; (*Focal Mechanism: Harvard Global CMT) rupture length, $450 \mathrm{~km}$; width, $150 \mathrm{~km}$; and slide range, $2500 \mathrm{~cm}$. The curved solid lines indicate inflation, while the curved dash lines represent compression. The star is the epicenter of the earthquake, the triangles represent the distributed observation stations, the purple lines are the faults, and the bright clear blue lines indicate rivers.

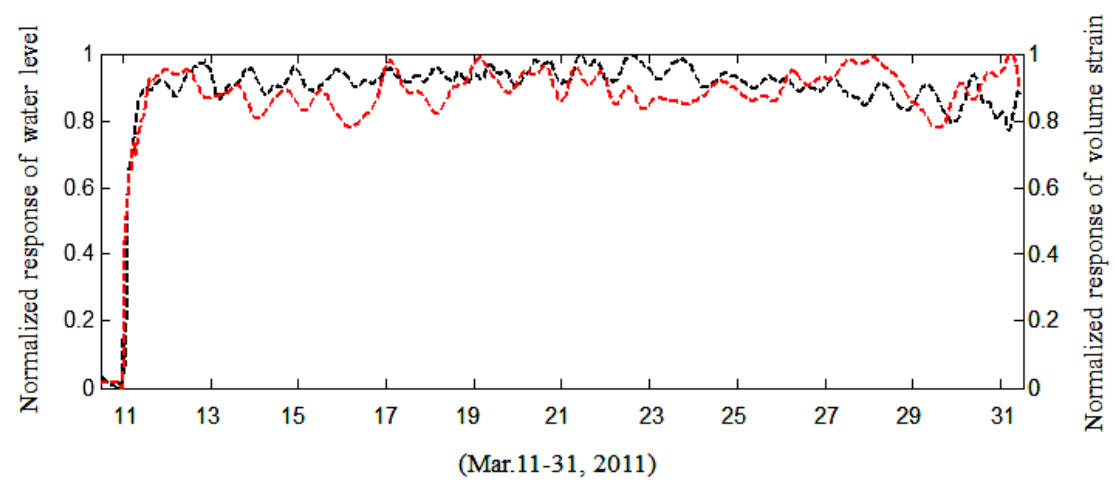

